\title{
Efficacy of antimicrobial lock solutions in preventing catheter-related blood stream infection in haemodialysis patients: a systematic review and meta-analysis of prospective randomised controlled trials
}

\author{
Ahmad Maifada Yakasaia*, Hamza Muhammad bc, Garba lliyasubc, Aisha Muhammad Naladocd, Mahmood Muhammad Dalhat ${ }^{\text {bc }}$, \\ Zaiyad Garba Habibe, Farouk Daiyabucc, Chinagozi Precious Edwinf, Musa Baba Maiyakicg and Daiyabu Alhaji lbrahim ${ }^{\mathrm{cg}}$ \\ aInfectious and Tropical Diseases Unit, Department of Medicine, Public Health and Diagnostic Institute, College of Medical Sciences, Northwest \\ University, Kano, Nigeria \\ 'Infectious and Tropical Diseases Unit, Department of Medicine, Bayero University, Kano, Nigeria \\ 'Aminu Kano Teaching Hospital, Kano, Nigeria \\ ${ }^{d}$ Nephrology and Haemodialysis Unit, Department of Medicine, Bayero University, Kano, Nigeria \\ 'Department of Medicine, University of Abuja Teaching Hospital, Abuja, Nigeria \\ ${ }^{f}$ Department of Microbiology, Aminu Kano Teaching Hospital, Kano, Nigeria \\ ${ }^{9}$ Department of Medicine, Bayero University, Kano, Nigeria \\ *Corresponding author, email: ahmadmaifada@gmail.com
}

\begin{abstract}
Background: Catheter-related blood stream infection (CRBSI) contributes to morbidity and mortality among patients on haemodialysis (HD). We carried out a systematic review and meta-analysis to assess the efficacy of antimicrobial lock solutions (ALS) in preventing CRBSI. Method: Electronic search of randomised controlled trials (RCTs) comparing ALS with other agents was performed up to January 2013. DerSimonian and Laird meta-analysis was performed to obtain pooled relative risk (RR) from which efficacy of ALS and numbers needed to treat (NNT) were calculated. In a restricted analysis, pooled RRs where compared using a test of interaction to calculate ratio of relative risks (RRR). Meta-regression analysis was employed to explore sources of heterogeneity. Results: Sixteen RCTs involving 2016 individuals met the inclusion criteria. The efficacy of ALS in preventing CRBSI was $80 \%$ with NNT of 3 patients to prevent one CRBSI. The RR of CRBSI was significantly lower with ALS compared with heparin-only lock solution [RR $\{95 \%$ confidence interval $(\mathrm{Cl})\}=0.20(0.13-0.31)]$. With low dose $(\leq 5 \mathrm{mg} / \mathrm{ml})$ and high dose $(40 \mathrm{mg} /$ $\mathrm{ml})$ gentamicin-containing ALS, the RR $(95 \% \mathrm{Cl})$ of developing CRBSI was 0.03 (0.01-0.13) and 0.18 (0.03-0.98), respectively, with no significant difference [RRR $(95 \% \mathrm{Cl})=0.2(0.02-1.61), p=0.126]$. Heterogeneity was explained by a statistically significant association between rate of CRBSI and catheter days $(p=0.037)$. Conclusion: ALS are effective in preventing CRBSI. Low dose gentamicin should be preferred over high dose gentamicin as an ALS because it offers similar benefit in preventing CRBSI with lesser risk of toxicity from systemic leakage and subsequent development of drug resistance.
\end{abstract}

Keywords: antimicrobials, blood stream infection, catheter, efficacy, haemodialysis, meta-analysis, systematic review

\section{Introduction}

Long-term renal replacement therapy in the form of haemodialysis (HD) is challenged by the prevention of catheterrelated infections mainly involving the blood stream, exit-site and tunnel. Catheters are commonly used among patients on HD when permanent vascular access has not been secured or is not ripe for dialysis. It has been reported that about $25 \%$ of all patients on HD have catheters and, at commencement of HD, up to $80 \%$ of patients required catheters. ${ }^{1}$ The risk of catheterrelated bloodstream infection (CRBSI) is high among catheterdependent HD patients. Serious life-threatening complications of CRBSI, such as infective endocarditis, may require several days of hospital admission and generate an increased financial burden on chronic HD patients. The morbidity and mortality in this group of patients is worsened by catheter-related infections. ${ }^{2}$

Factors associated with the host, catheter, microorganism and dialysis interact to predispose catheter-dependent patients to the risk of developing CRBSI.,4 Bacteria that colonise catheters are usually located within a protective polysaccharide secretion commonly called a biofilm matrix, which has to be eradicated in order to prevent CRBSI. Guidelines on prevention of CRBSI initially emphasised on aseptic technique of catheter insertion, exit site dressing, catheter maintenance and prompt removal of the catheter when needed. ${ }^{5}$ However, with better understanding of the concept of biofilms, antimicrobial lock solutions (ALS) were used in the prevention of CRBSI. ${ }^{6}$ Antibiotics commonly used as ALS include gentamicin, amikacin, ciprofloxacin, cefotaxime, ceftazidime, cefazolin, minocycline and vancomycin.? Non-antibiotic agents with good antimicrobial properties are also used in ALS and include antiseptics, such as alcohol, citrate and taurolidine. ${ }^{7} \mathrm{ALS}$ are formed by putting these agents into the catheter lumen together with an anticoagulant, such as heparin.? Various studies have reported on the potential of ALS in preventing CRBSI, ${ }^{8-14}$ as well as prolonging the time of onset of the first episode of CRBSI. ${ }^{15}$ However there has been conflicting reports on the efficacy and potential risk of toxicity associated with the use of these agents among HD patients. We conducted this systematic review and meta-analysis of prospective randomised controlled trials (RCTs) to obtain pooled estimates of efficacy of ALS in preventing CRBSI. 


\section{Methods \\ Data bases search}

Both electronic and manual search of relevant publications were conducted up to January 2013. Medline, Google Scholar, Excerpta Medical dataBASE (EMBASE), Web of Science, Cochrane data base, African Journals Online (AJOL), systematic reviews, infectious disease journals, nephrology journals and other websites were searched for English language publications on CRBSI in HD patients. Medical sub-heading (MeSH) terms used in different combinations in the search included:

- 'Catheter-related infection',

- 'Catheter-associated infection',

- 'Bacteraemia',

- 'Septicaemia',

- 'Blood stream infection',

- 'Line-associated infection,'

- 'Intravascular catheter',

- 'Antimicrobial lock',

- 'Antibiotic lock',

- 'Randomised controlled trial',

- 'Clinical trial', and

- 'Haemodialysis'.

Also manual search of references of all relevant studies and reviews was performed.

\section{Inclusion and exclusion criteria}

Studies included satisfied the following criteria:

(1) All were RCTs;

(2) Involved only adults 18 years and above;

(3) Used intraluminal ALS either alone or in combination with an anticoagulant for the prevention of CRBSI;

(4) Provided relative risk (RR) of CRBSI in both treatment and control groups, or had provided enough data to derive the RR; and,

(5) Reported incidence of CRBSI per 1000 catheter days.

Studies were excluded if they did not satisfy the inclusion criteria. Three reviewers independently assessed each study for eligibility. A fourth reviewer resolved disagreement between the reviewers when encountered.

\section{Data extraction}

Data was obtained using a standardised form. The information extracted included name of author, country, year of publication, demographic characteristics, study design, clinical and laboratory characteristics, type of catheter, ALS used, care of catheter exit site, catheter days, incidence of CRBSI and number of infections reported in each group.

\section{Statistical analysis}

RR with 95\% confidence interval (Cl) was computed for each trial. RR was defined as the risk of CRBSI in the treatment group divided by the risk of CRBSI in the control group. The log RR and the standard error of the log RR were computed for each trial. Also the logarithm of the incidence of CRBSI was computed for all the comparison groups. When no event was reported in one of the groups we added 0.5 to both the numerator and denominator of both groups before calculating the RR. ${ }^{16}$ DerSimonian and Laird meta-analysis using random effect model (REM) or fixed effect model (FEM) was done on the RR and incidence estimates to obtain pooled results. The efficacy of ALS was determined by subtracting the risk difference from 1 , whereas the number needed to treat (NNT) was calculated as the reciprocal of the risk difference. ${ }^{17}$ In a restricted analysis, different RRs were compared using test of interaction to determine ratio of relative risk (RRR), $95 \% \mathrm{Cl}$ and $p$-value. ${ }^{18} \mathrm{We}$ examined publication bias using Begg's test, while small study effect was analysed using Egger's test. ${ }^{19,20}$ Due to the inconsistency associated with these tests, publication bias was assumed present only if all the $p$-values in Begg's and Egger's tests were significant. ${ }^{21,22}$ Sensitivity analysis was done to investigate the influence of single trial on pooled estimate. ${ }^{23}$ Heterogeneity was assessed with $\mathrm{I}$-squared statistics $\left(\mathrm{I}^{2}>50 \%\right.$ indicates substantial heterogeneity). Study-level parameters associated with risk of CRBSI were explored via univariable, weighted, least squares meta-regression analysis. The Grading of Recommendations Assessment Development and Evaluation (GRADE) approach was used to assess the quality of included studies and the quality of clinical evidence. ${ }^{24,25}$ Quality is down-graded if the study design is not a RCT, and if there are study limitations, inconsistency (substantial heterogeneity), imprecision, indirectness or publication bias. Imprecision is suggested by small sample size or wide/overlapping $\mathrm{Cl}^{25}$ Where no justification for sample size was provided, we considered sample size adequate if at least 100 subjects were analysed. ${ }^{26}$ Quality is up-graded where there is an exposure-response gradient, large effect size (ES) and no plausible confounding. ${ }^{25}$ Appropriate formula was used to compute the ESs and were classified according to Cohen's method of small ES (up to 0.49 ), moderate ES $(0.5-0.79)$ and large ES ( $\geq 0.8) .{ }^{27}$ Data analysis was performed with Stata version 12.0 and GRADEprofiler version 3.6.1.

\section{Results}

\section{Description of included trials}

Sixteen RCTs satisfied the inclusion criteria, ${ }^{8-11,14,15,28-36}$ and one of them had an additional sub-study ${ }^{10}$ making a total of 17 studies that were analysed (Figure 1). The trials were reported between 2002 and 2012 and involved 2016 individuals across 9 countries. Four studies were done in the United States of America (USA), 3 in Saudi Arabia, 2 in Iran and one study each from England, Brazil, Netherlands, United Kingdom (UK), Canada, Korea and Australia. Other details are given in Table 1.

\section{Quality assessment of included trials}

Adequate concealment allocation was reported in seven ${ }^{8,9,12,14,15,35,36}$ trials while six trials were doubleblinded. 8,12,14,15,35,36 Analysis by intention-to-treat (ITT) was performed in 10 trials. ${ }^{8,9,11,14,15,29-31,33-35}$ All included trials were randomised and had reported measures to curtail bias. Other parameters assessed were sample size, loss to follow-up, missing data management, confounders and baseline characteristics. According to the GRADE approach, two ${ }^{14,34}$ of the studies were of high quality, thirteen ${ }^{8-12,15,28,30-33,35,36}$ studies were of moderate quality and two $0^{11,29}$ had low quality as shown in Table 2 .

\section{Characteristics of participants in the included trials}

The trials involved 2016 adults on HD with a follow-up period of 6 to 12 months. The mean catheter days for trials reported from 2002 to 2007 and 2010 to 2012 was 5293 and 15369 days, respectively [mean difference $(95 \% \mathrm{Cl})=10076$ (2349 to 17803), $p=0.01]$. The mean age of participants reported in 14 trials ranged from 48.3 to 66.3 years and 44.7 to 62.8 years for the 


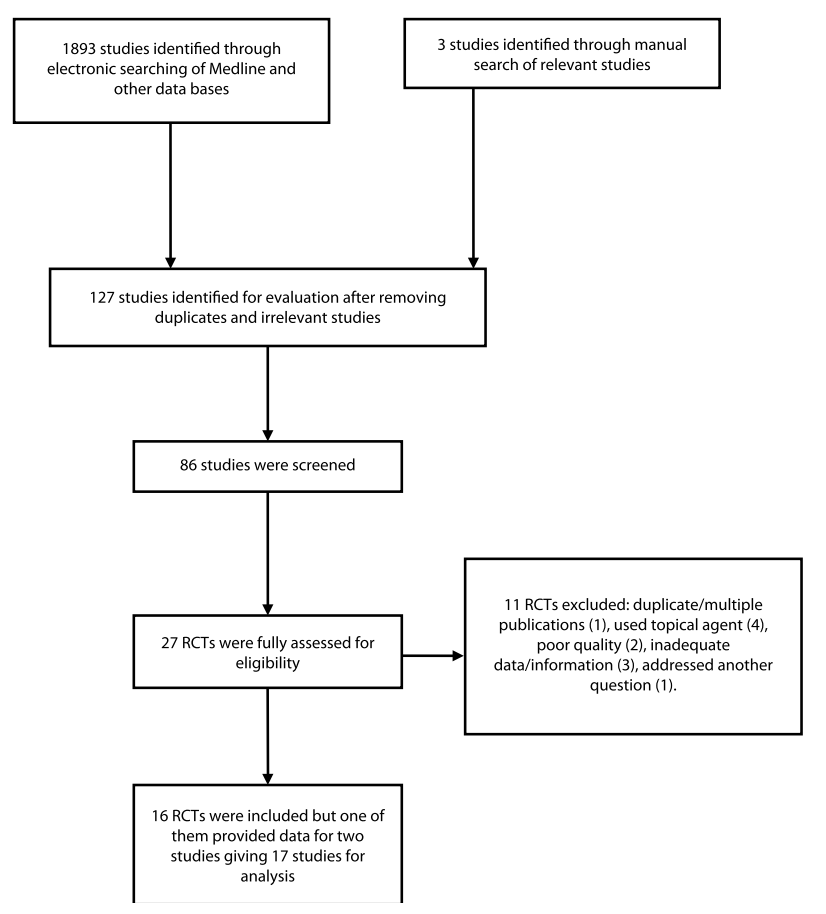

Figure 1: Flowchart of studies selection.

treatment and control groups, respectively. The proportion of female participants reported in 12 trials was $28 \%$ to $74 \%$ for the treatment group and $39.6 \%$ to $60 \%$ for the control group. The range of mean packed cell volume (PCV) reported in 8 trials was $26.4 \%$ to $33.5 \%$ for the treatment group and $27 \%$ to $34.5 \%$ for the control group.

The concentration of gentamicin used in the trials ranged from $0.32 \mathrm{mg} / \mathrm{ml}$ to $40 \mathrm{mg} / \mathrm{ml}$. One of the trials that used $40 \mathrm{mg} / \mathrm{ml}$ of gentamicin reported median predialysis levels of $2.8 \mathrm{mg} / \mathrm{ml}$ with a range of 0.6 to $3.5 \mathrm{mg} / \mathrm{ml}$ among 42 patients randomised to gentamicin. ${ }^{8}$ Symptoms of ototoxicity were reported in 4 of these 42 patients on high dose intraluminal gentamicin. However, with low dose gentamicin $(5 \mathrm{mg} / \mathrm{ml})$, Mclntyre et al. reported that all random gentamicin levels were $<0.2 \mathrm{mg} / \mathrm{ml}$ and no patient complained of toxicity symptoms, though long term toxicity to such low levels could not be ruled out. ${ }^{9}$ In another trial, Al-Hweish et al. reported that $40 \mathrm{mg} / \mathrm{ml}$ of gentamicin resulted in undetectable levels in $93.94 \%$ of patients and $<0.001 \mathrm{mg} / \mathrm{ml}$ in $6.6 \%$ of patients. ${ }^{30}$ None of the trials using gentamicin assessed hearing impairment. After 3 years of extensive use of gentamicin lock solutions, there was no emergence of resistance from the centers where one of the included RCTs was conducted. ${ }^{34}$ Vancomycin at $25 \mathrm{mg} / \mathrm{ml}$ was reported to be undetectable in $90.1 \%$ of patients and $<0.0005 \mathrm{mg} / \mathrm{ml}$ in $9.9 \%$ of patients. ${ }^{30}$ Manufacturers of ALS and/or the process of preparation by a pharmacist or nurse were reported in 9 trials. ${ }^{10,12,14,15,29,31,33,35,36}$ One trial described detailed precautions taken to ensure stability of ALS during the study period. In vitro bactericidal efficacy of the ALS was also microbiologically evaluated in that trial. ${ }^{10}$

Most of the trials excluded participants with tunnel infection, exit site infection, localized/systemic infection, drug allergy, pregnant women and prolonged antibiotic usage. One trial excluded subjects with catheter blood flow rates $<300 \mathrm{ml} / \mathrm{min}^{35}$ Prophylactic use of antibiotics was employed in only one trial where a single dose of intravenous cephalothin was given to all the patients before catheter insertion. ${ }^{8}$ In all the other trials patients were not on simultaneous systemic antibiotic therapy either for prophylaxis or treatment. In one of the trials, it was reported that one patient that was randomised to the heparin group developed endocarditis requiring valve replacement. ${ }^{31}$

\section{Findings from meta-analysis}

When all the 16 trials were included the REM pooled RR of CRBSI per patient was significantly lower with ALS compared with heparin alone lock solution ( $\mathrm{RR}=0.20 ; 95 \% \mathrm{Cl}=0.13-0.31$ ) (Figure 2). Heterogeneity was statistically significant $\left({ }^{2}=85.8 \%\right.$, $p<0.0001$ ). No publication bias (Begg's test, $p=0.064$; Egger's test, $p=0.513$ ) (see Figures 3 and 4). Sensitivity analysis showed no trial unduly weighed on the estimate. The REM pooled RR of developing CRBSI among the ALS and heparin group was 0.10; $95 \% \mathrm{Cl}=0.08-0.12$ and $0.40 ; 95 \% \mathrm{Cl}=0.30-0.51$, respectively. Thus, the efficacy of ALS in preventing CRBSI was $80 \%$ with NNT of 3.3 .

\section{Restricted analysis}

When 5 trials that used gentamicin in combination with citrate/ heparin were combined the REM pooled RR $(95 \% \mathrm{Cl})$ of CRBSI was $0.06(0.01-0.25)$. No publication bias (Begg's test, $p=1.000$, Egger's test, $p=0.034){ }^{8-10,28,34}$ The concentrations of gentamicin used in these trials were $40 \mathrm{mg} / \mathrm{ml}, 5 \mathrm{mg} / \mathrm{ml}, 4 \mathrm{mg} / \mathrm{ml}$ and $0.32 \mathrm{mg} / \mathrm{ml}$ as shown in Table 1. From 3 trials that used low dose gentamicin $(0.32 \mathrm{mg} / \mathrm{ml}$ to $5 \mathrm{mg} / \mathrm{ml})$ in combination with citrate/ heparin the REM pooled RR $(95 \% \mathrm{Cl})$ of CRBSI was $0.03(0.01$ 0.13). ${ }^{9,10,34}$ The FEM pooled RR ( $95 \% \mathrm{Cl}$ ) of CRBSI from 2 trials that used high dose gentamicin $(40 \mathrm{mg} / \mathrm{ml})$ in combination with citrate was 0.18 (0.03-0.98) ${ }^{8,28}$ Comparison of RRs derived from trials that used low dose and high dose gentamicin yielded RRR $(95 \% \mathrm{Cl})$ of $0.2(0.02-1.61), p=0.126$.

From 2 trials that compared cefotaxime containing ALS with control the REM pooled RR $(95 \% \mathrm{Cl})$ of CRBSI was $0.38(0.32$ 0.44). . $^{12,36}$ Two trials also compared minocycline containing ALS with control and the REM pooled RR $(95 \% \mathrm{Cl})$ of CRBSI was 0.24 (0.10-0.56). ${ }^{10,31}$ Another 2 trials compared gentamicin combined with either vancomycin or cefotaxime ALS with control and the REM pooled RR (95\% CI) of CRBSI was $0.12(0.05-0.29) .{ }^{11,30}$ Nonantibiotic ALS (Taurolidine and/or Citrate) where compared with control in 3 trials and the FEM pooled RR $(95 \% \mathrm{CI})$ of CRBSI was $0.44(0.31-0.62) .{ }^{14,15,29}$

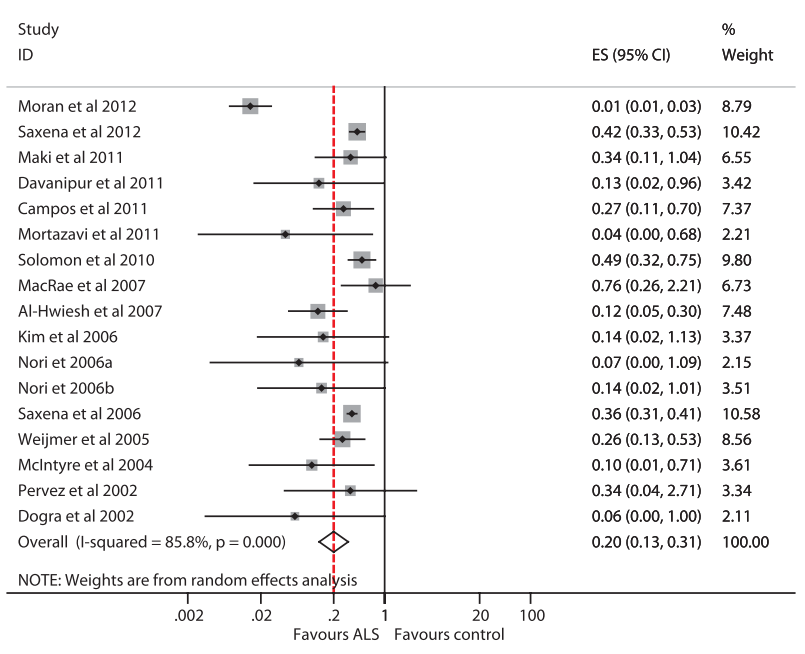

Figure 2: Forest plot showing RR of developing CRBSI among patients on chronic HD. 
Table 1: Characteristics of studies included in the meta-analysis

\begin{tabular}{|c|c|c|c|c|c|c|}
\hline Author & Sample size & $\begin{array}{l}\text { Catheter days } \\
\text { (ALS, controls) }\end{array}$ & Catheter type & Catheter care & CRBSI definition & ALS \\
\hline Moran et al. $(2012)^{34}$ & 303 & 39827,32933 & TCC & Triple antibiotic* & Non-CDC & $\begin{array}{c}\text { GTC- } 0.32 \mathrm{mg} / \mathrm{ml}, \\
\text { CTR- } 4 \%\end{array}$ \\
\hline Saxena et al. $(2012)^{36}$ & 82 & 14965,17155 & TCC & Non & $\mathrm{CDC}$ & CFO- $10 \mathrm{mg} / \mathrm{ml}$ \\
\hline Maki et al. $(2011)^{33}$ & 407 & 25266,24390 & Not clear & NA & Non-CDC & $\begin{array}{c}\text { CTR-7.5\%, MB, MP, } \\
\text { PPP }\end{array}$ \\
\hline $\begin{array}{l}\text { Davanipur et al. } \\
(2011)^{32}\end{array}$ & 100 & 1750,1625 & TCC & NA & NA & CLOX-100 mg/ml \\
\hline $\begin{array}{l}\text { Campos et al. } \\
(2011)^{31}\end{array}$ & 187 & 4371,4376 & TCC/NTC & $\begin{array}{l}\text { Chlorhexidine/ } \\
\text { alcohol }\end{array}$ & $\mathrm{CDC}$ & $\begin{array}{c}\text { MNC-3 mg/ml, EDTA- } \\
30 \mathrm{mg} / \mathrm{ml}\end{array}$ \\
\hline $\begin{array}{l}\text { Mortazavi et al. } \\
(2011)^{33}\end{array}$ & 30 & NA & TCC & $\begin{array}{l}\text { Antiseptic/topical } \\
\text { mupirocin }\end{array}$ & $\mathrm{CDC}$ & CFO- $10 \mathrm{mg} / \mathrm{ml}$ \\
\hline $\begin{array}{l}\text { Solomon et al. } \\
(2010)^{15}\end{array}$ & 107 & 8129,9642 & TCC & $\begin{array}{l}\text { Chlorhexidine/ } \\
\text { alcohol }\end{array}$ & Non-CDC & TRD-1.35\%, CTR- 4\% \\
\hline $\begin{array}{l}\text { Al-Hwiesh et al. } \\
(2007)^{30}\end{array}$ & 63 & 7212,7656 & TCC & lodine solution & $\mathrm{CDC}$ & $\begin{array}{c}\text { VCM- } 25 \mathrm{mg} / \mathrm{ml}, \text { GTC- } \\
40 \mathrm{mg} / \mathrm{ml}\end{array}$ \\
\hline $\begin{array}{l}\text { MacRae et al. } \\
(2008)^{29}\end{array}$ & 61 & 92,105 & TC & NA & Non-CDC & CTR- $4 \%$ \\
\hline Saxena et al. $(2006)^{12}$ & 96 & 18615,21170 & TCC & $\begin{array}{l}\text { Oxygen permeable } \\
\text { dressing }\end{array}$ & $\mathrm{CDC}$ & CFO- $10 \mathrm{mg} / \mathrm{ml}$ \\
\hline Kim et al. (2006) ${ }^{11}$ & 120 & 1884,1233 & NTC & NA & Non-CDC & $\begin{array}{c}\text { CFZ- } 10 \mathrm{mg} / \mathrm{ml}, \mathrm{GTC}- \\
5 \mathrm{mg} / \mathrm{ml}\end{array}$ \\
\hline Nori et al. $(2006)^{10}$ & 61 & 4455,1734 & TCC & NA & $\mathrm{CDC}$ & $\begin{array}{c}\text { a) GTC-4 mg/ml, } \\
\text { CTR-3.13\%, or b). } \\
\text { MNC-3 mg/ml, EDTA- } \\
30 \mathrm{mg} / \mathrm{ml}\end{array}$ \\
\hline $\begin{array}{l}\text { Weijmer et al. } \\
(2005)^{14}\end{array}$ & 291 & 8431,8116 & TCC/NTC & NA & $\mathrm{CDC}$ & CTR-30\% \\
\hline $\begin{array}{l}\text { Mclntyre et al. } \\
(2004)^{9}\end{array}$ & 50 & 3252,2470 & TCC & $\begin{array}{l}\text { Oxygen permeable } \\
\text { dressing }\end{array}$ & $C D C$ & GTC-5 mg/ml \\
\hline Pervez et al. $(2002)^{28}$ & 36 & 1613,1311 & TCC & lodine & Non-CDC & $\begin{array}{c}\text { GTC- } 40 \mathrm{mg} / \mathrm{ml}, \mathrm{CTR}- \\
46.7 \%\end{array}$ \\
\hline Dogra et al. $(2002)^{8}$ & 83 & 3280,2643 & TCC & $\begin{array}{l}\text { Chlorhexidine/ } \\
\text { iodine }\end{array}$ & $\mathrm{CDC}$ & $\begin{array}{c}\mathrm{GTC}-40 \mathrm{mg} / \mathrm{ml}, \mathrm{CTR}- \\
3.13 \%\end{array}$ \\
\hline
\end{tabular}

*Neomycin, bacitracin and polymyxin

ALS: Antimicrobial lock solution; CRBSI: Catheter related blood stream infection; CDC: Center for Disease Control and Prevention; CFZ: cefazolin; CFO: cefotaxime; CTR: citrate; CLOX: cloxacillin; EDTA: ethylene diamino acetic acid; GTC: gentamicin; MB: methylene blue; MP: methylparaben; MNC: minocycline; NA: not available; NTC: Nontunneled cuffed catheter; PPP: propylparaben; TRD: taurolidine; TCC: tunneled cuffed catheter; VCM: vancomycin

\section{Quality of clinical evidence}

As shown in Table 3 the quality of clinical evidence was high for low dose gentamicin and moderate for high dose gentamicin, cefotaxime, minocycline and taurolidine/citrate.

\section{Meta-regression}

Metaregression analysis involving all the 16 studies that reported catheter days showed no association between rate of CRBSI and catheter days. However, when the two studies ${ }^{28,29}$ with $<3000$ catheter days were excluded meta-regression analysis showed significant association between rate of CRBSI and catheter days (slope curve coefficient $=2.35, p=0.037,95 \% \mathrm{Cl}=-1.1406$ to +0.0001 ) (see Figure 5). Rate of CRBSI rises with increasing proportion of diabetic patients though did not reach statistical significance (slope curve coefficient $=1.79, p=0.099,95 \%$ $\mathrm{Cl}=-0.001$ to +0.01$)$. There was a trend towards decreasing rate of CRBSI with increasing PCV though not statistically significant (slope curve coefficient $=-0.53, p=0.610,95 \% \mathrm{Cl}=-0.001$ to +0.0063$)$.

\section{Discussion}

This systematic review and meta-analysis of 16 RCTs involved 2016 adults with 279701 catheter days. The treatment and the control groups had similar demographic and laboratory characteristics. The two different statistical tests used did not detect publication bias and, where heterogeneity was encountered between studies, estimates were derived using REM.

The risk of CRBSI was significantly lower in ALS group as compared to heparin only lock group with an efficacy of $80 \%$. The risk of CRBSI in the heparin only lock group was 4 times that of the ALS group translating into NNT of 3 patients to prevent one CRBSI. All the RCTs included in the meta-analysis compared ALS with heparin and none conducted a head-to-head comparison of antibiotics. Hence, it is difficult to determine the most effective ALS in preventing CRBSI. Precipitation of antibiotics in heparin solution was not reported among all the seven trials that used antibiotics in heparin., ${ }^{911,12,30,32,35,36}$ It is believed that precipitation is concentration dependent and more likely to occur with high concentration of antibiotics in low concentration of heparin. ${ }^{37}$ With the exception of one trial, ${ }^{9}$ all the other trials have applied this principle because those trials using high ${ }^{12,30,35,36}$ concentration of antibiotics used high concentration of heparin $(5000 \mathrm{IU} / \mathrm{ml})$ while those using low ${ }^{11,32}$ concentrations of antibiotics have used low concentration of 
Table 2: Assessment of study quality using the GRADE approach

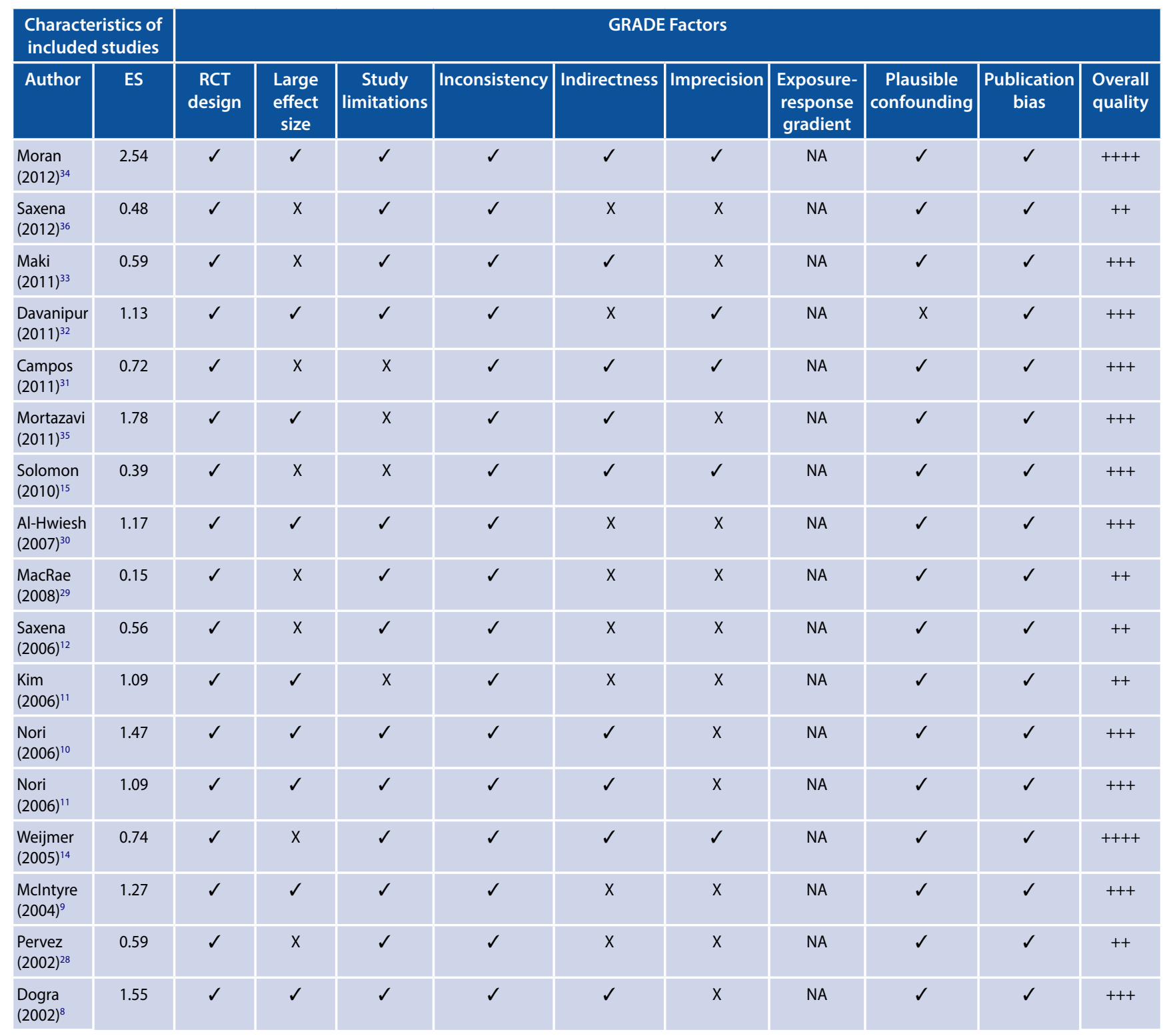

$\checkmark$ - No serious limitation, inconsistency, indirectness, imprecision, publication bias, plausible confounding (or presence of large effect size and exposure-response gradient) $\mathrm{X}$ - Presence of serious limitation, inconsistency, indirectness, imprecision, publication bias, plausible confounding (or absence of large effect size and exposure-response gradient)

Overall quality of evidence: + - very low; ++ - low; +++ - moderate; ++++ - high

RR: relative risk; Cl: confidence interval; GRADE: Grading of Recommendations Assessment Development and Evaluation; NA: not available; ES: effect size

heparin $(1000 \mathrm{lU} / \mathrm{ml})$. The trial that used low concentration of gentamicin $(5 \mathrm{mg} / \mathrm{ml})$ in high concentration of heparin (50000 IU/ $\mathrm{ml}$ ) reported no systemic heparinisation. ${ }^{9}$

Gentamicin was the most common antibiotic used in the trials and showed significant benefit in reducing CRBSI. Low dose gentamicin lock solution appeared to show similar benefit in preventing CRBSI compared to high dose gentamicin lock solution. In addition, low dose gentamicin is associated with a lesser risk of toxicity from systemic leakage and subsequent development of drug resistance. One of the included RCTs that used low dose gentamicin $(0.32 \mathrm{mg} / \mathrm{ml})$ reported no emergence of resistance to gentamicin from their center from 2008 to 2012, despite routine usage as a catheter locking agent. ${ }^{34} \mathrm{~A} 7$-year longitudinal study involving chronic HD patients used $5 \mathrm{mg} / \mathrm{ml}$ gentamicin in $1 \%$ Heparin with a mean (range) trough level of $170(50-310) \mathrm{mg} / \mathrm{ml}$ among the cohort. They reported no resistance to gentamicin and no ototoxicity after 7 years of follow-up..$^{38}$ In contrast, use of high dose gentamicin $(40 \mathrm{mg} / \mathrm{ml})$ as a catheter lock is associated with systemic exposure to gentamicin in one of the included RCTs, and could potentially predispose patients to drug toxicity and development of drug resistant microorganisms. ${ }^{8}$ Only one study so far reported gentamicin-resistant microorganisms in HD patients using gentamicin as a catheter locking agent to prevent CRBSI. ${ }^{39}$ However, the reliability of this finding is limited by the uncontrolled retrospective design of the study. Vancomycinresistant Staphylococcus aureus $(\mathrm{VRSA})^{40}$ has also been documented; and this is a major concern as both gentamicin and vancomycin are routinely used in the treatment of CRBSI. ${ }^{31}$ Minocycline is not routinely used in management of CRBSI and has been found to be very potent in eradicating microorganisms inside biofilm, ${ }^{41}$ while cefotaxime has a good safety profile in HD and severely ill patients. ${ }^{42,43}$ Cardiotoxicity and catheter blockage are associated with trisodium citrate and taurolidine citrate 


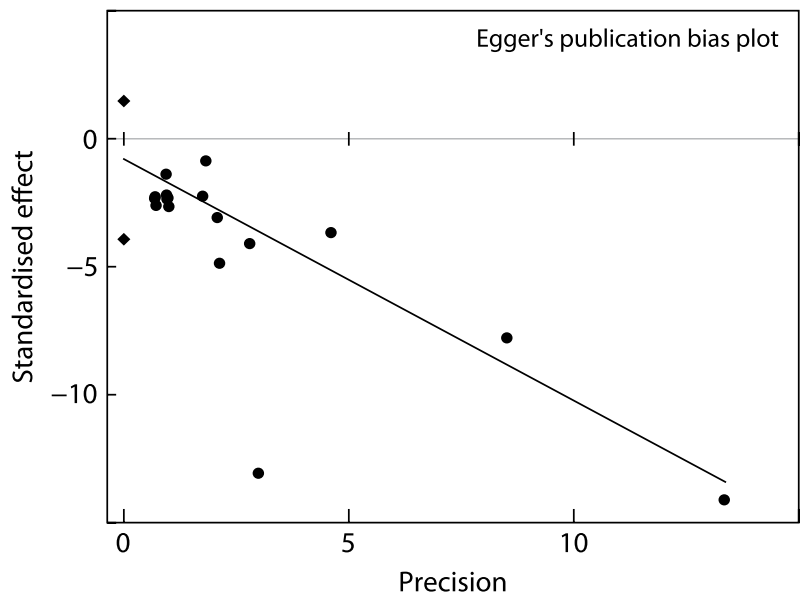

Figure 3: Egger's plot assessing small study effect.

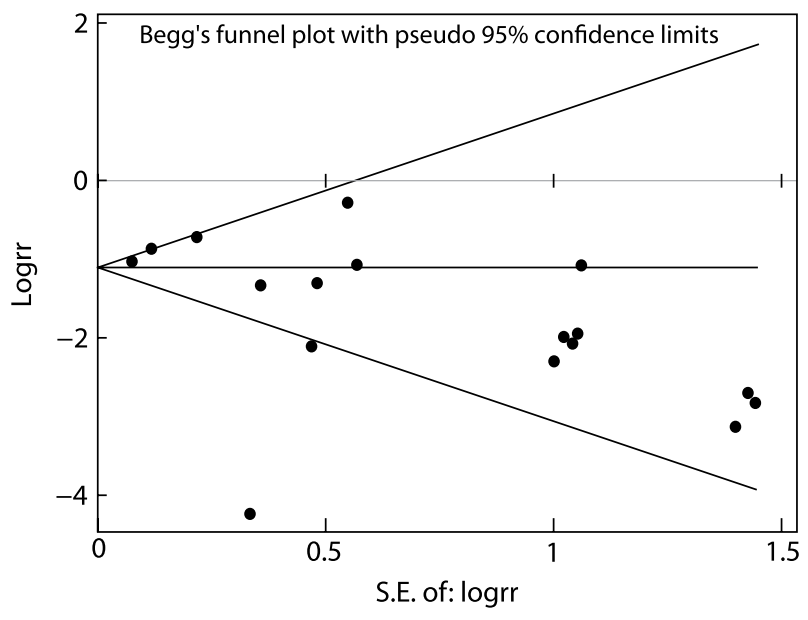

Figure 4: Begg's Funnel plot assessing publication bias.

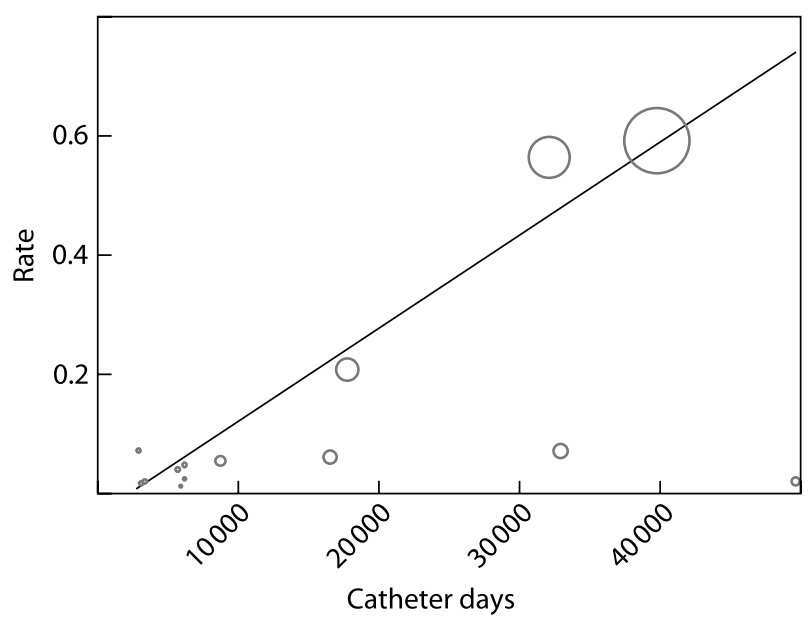

Figure 5: Meta-regression of RR of developing CRBSI by catheter days. Slope curve coefficient $=2.35, p=0.037,95 \% \mathrm{Cl}=-1.1406$ to +0.0001 .

when used as catheter lock solutions. ${ }^{36}$ There has been concern about the efficacy and safety of citrate at varying concentrations. Adverse effects are common at higher concentrations of citrate, ${ }^{44}$ while low concentrations were found to be ineffective in preventing CRBSI. ${ }^{45}$

A major challenge with diagnosis of CRBSI in routine clinical practice is that signs of inflammation at the catheter insertion site may not accurately predict CRBSI ${ }^{46}$ Majority of the included studies used CDC criteria to define CRBSI. Although this criterion has high sensitivity, its poor specificity for CRBSI is a major concern. ${ }^{47}$ All the included RCTs reported Staphylococcus aureus among ALS and heparin groups causing CRBSI. End-stage renal disease (ESRD) patients receiving HD are at increased risk of developing Staphylococcus aureus septicemia, ${ }^{48,49}$ a condition associated with a longer stay in hospital with a high cost of treatment. ${ }^{50}$ Endocarditis requiring valve replacement occurred in a patient on the heparin lock solution in one of the trials. In that trial the most common bacteria cultured from blood in the heparin lock group were Staphylococcus aureus, coagulase negative Staphylococcus, E. coli and Enterobacter aerogenes, in that order. ${ }^{31}$ The mortality rate has been reported to be higher among patients hospitalised with Staphylococcus aureus bacteremia as compared to those with Staphylococcus aureus non-blood stream infection..$^{50}$ Apart from infective endocarditis, other life-threatening complications that could occur in the setting of Staphylococcus aureus septicemia include meningitis and metastatic abscesses. ${ }^{51,52}$ Use of topical or intranasal mupirocin ${ }^{8,14,35}$ and triple antibiotic ointment ${ }^{34}$ for catheter care in some of the trials in this meta-analysis could affect the type of microorganism cultured in patients with CRBSI. Bacterial biofilm usually originates from the normal bacterial flora on the skin at the exit-site of the catheter. ${ }^{53}$ In the trial by Dogra et al., nasal mupirocin was given for prophylaxis against CRBSI. This could have lead to the predominance of gram-negative CRBSI over Staphylococcus aureus CRBSI as explained by the authors. ${ }^{8}$

Cost and availability are important factors in healthcare intervention which could influence the process of decision making. Among the trials included in this review only three recognise the cost of ALS. ${ }^{10,11,14}$ Citrate is more expensive than heparin but readily available, whereas taurolidine is also expensive but not readily available. The monthly cost of gentamicin/citrate lock solution per-patient is 4 times that of minocycline/ethylene diamino acetic acid lock solution. ${ }^{10}$ Complete treatment of an episode of CRBSI could cost up to US\$25 000 to US\$45 $000 . .^{54}$ In addition, CRBSI increases cost of hospitalisation and duration of hospital stay. ${ }^{53}$ Hours of productivity lost during admission for CRBSI together with drug and non-drug costs associated with CRBSI adds to the financial burden imposed by ESRD. Prophylactic ALS could reduce this financial burden of CRBSI incurred by patients. A conservative analysis estimated that a $50 \%$ reduction in episodes of CRBSI from prophylactic ALS could save patients up to US $\$ 5,000$ per annum. ${ }^{55}$ However, this cost benefit could easily be abolished by development of drug-resistant microorganisms that require prolonged hospital stays and expensive antibiotics. ${ }^{56}$

Accuracy of ESs derived in this meta-analysis could be limited by some methodological factors in the trials. Predictive value measures such as sensitivity and specificity of the non-CDC definition of CRBSI used in some of the RCTs may not be as good as that of CDC definition. Proper assessment of drug toxicity and development of drug-resistant microorganisms was not possible due to the short duration of the follow-up period in some of the trials. Only one trial reported precautions taken to ensure stability of the ALS during the study period..$^{10}$ Further, in vitro stability of antibiotics in heparin lock solutions was not tested in all seven trials which used antibiotics in heparin solution. 9,11,12,30,32,35,36 However, this is unlikely to affect results of the meta-analysis because none of these studies reported precipitation of antibiotics in heparin solution. Strength of this meta-analysis includes a large sample size and number of 
Table 3: Assessment of quality of clinical evidence and strength of recommendation using the GRADE approach

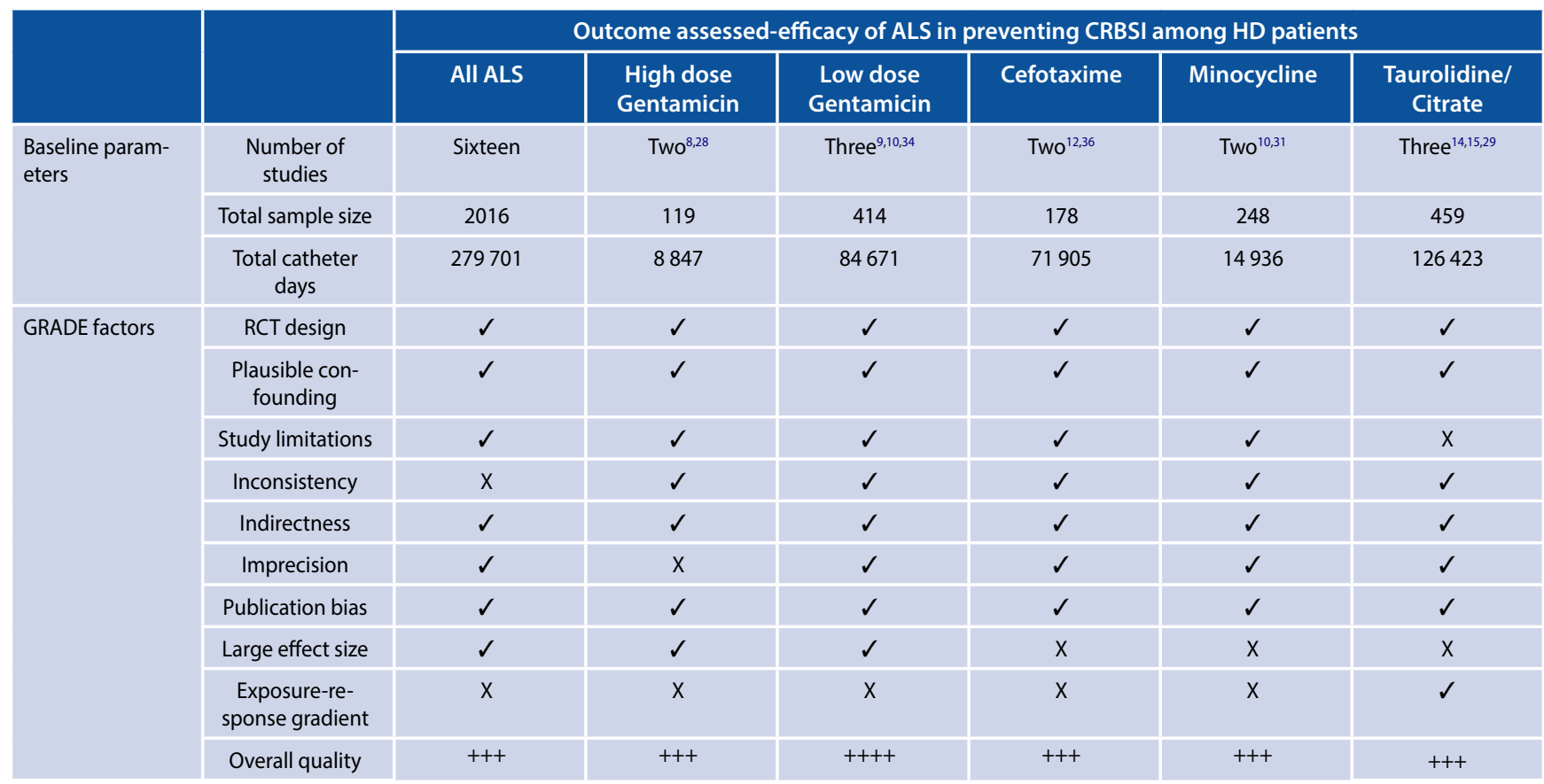

$\checkmark$ - No serious limitation, inconsistency, indirectness, imprecision, publication bias, plausible confounding (or presence of large effect size and exposure-response gradient) $\mathrm{X}$ - Presence of serious limitation, inconsistency, indirectness, imprecision, publication bias, plausible confounding (or absence of large effect size and exposure-response gradient)

Overall quality of evidence: + - very low; ++ - low; +++ - moderate; ++++ - high

ALS: Antimicrobial lock solution; CRBSI: Catheter-related blood stream infection; GRADE: Grading of Recommendations Assessment Development and Evaluation; HD: Haemodialysis

catheter days. In comparison to previously conducted metaanalyses, ${ }^{57,58}$ this study included recently published articles and this allowed for restricted analysis with respect to low and high dose gentamicin. Moreover, application of the GRADE system of assessing quality of studies provided opportunity for rating strength of clinical recommendations.

In conclusion, ALS are effective in preventing CRBSI although drug toxicity is a major concern. Low dose gentamicin should be preferred to high dose gentamicin as it offers similar benefit in preventing CRBSI with lesser risk of toxicity from systemic leakage and subsequent development of drug resistance. Further studies are needed for a head-to-head comparison of antimicrobial agents in order to provide guidelines for clinical practice.

Conflict of interest - We declare that we have no conflicts of interest.

\section{References}

1. Collins AJ, Foley RN, Gilbertson DT, et al. The state of chronic kidney disease, ESRD, and morbidity and mortality in the first year of dialysis. Clin J Am Soc Nephrol. 2009;4(Suppl 1):S5-S11.

2. Fysaraki M, Samonis G, Valachis A, et al. Incidence, clinical, microbiological features and outcome of bloodstream infections in patients undergoing hemodialysis. Int J Med Sci. 2013;10(12):1632-8.

3. Katneni R, Hedayati SS. Central venous catheter-related bacteremia in chronic hemodialysis patients: epidemiology and evidence-based management. Nat Clin Pract Nephr. 2007;3(5):256-66.

4. Allon M, Depna TA, Radeva M, et al. Impact of dialysis dose and membrane on infection-related hospitalization and death: results of the HEMO study. J Am Soc Nephrol. 2003;14(7):1863-70.

5. Scott RD. The direct medical costs of health-care associated infections in US hospitals and the benefits of prevention. Atlanta, GA; 2009.

6. Aslam S. Effects of antibacterials on biofilm. Am J Infect Control 2008;36(10):S175.e 9-11. doi: 10.1016/j.ajic.2008.10.002.
7. Weber DJ, Rutala WA. Central Line-Associated Bloodstream Infections: Prevention and Management. Infectious Disease Clinics of North America 2011;25:77-102.

8. Dogra GK, Herson H, Hutchison B, et al. Prevention of Tunneled Hemodialysis Catheter-Related Infections Using Catheter-Restricted Filling with Gentamicin and Citrate: A Randomized Controlled Study. J Am Soc Nephrol. 2002;13:2133-9.

9. McIntyre CW, Hulme LJ, Taal M, et al. Locking of tunneled hemodialysis catheters with gentamicin and heparin. Kidney Int. 2004;66:801-5.

10. Nori US, Manoharan A, Yee J, et al. Comparison of low-dose gentamicin with minocycline as catheter lock solutions in the prevention of catheter-related bacteremia. Am J Kidney Dis. 2006;48:596-605.

11. Kim SH, Song KI, Chang JW, et al. Prevention of uncuffed hemodialysis catheter-related bacteremia using an antibiotic lock technique: a prospective, randomized clinical trial. Kidney Int. 2006;69:161-4.

12. Saxena AK, Panhotra BR, Sundaram DS, et al. Tunneled catheters' outcome optimization among diabetics on dialysis through antibiotic-lock placement. Kidney Int. 2006;70:1629-35.

13. Allon M. Prophylaxis against dialysis catheter-related bacteremia with a novel antimicrobial lock solution. Clin Infect Dis. 2003;36(12):153944.

14. Weijmer MC, van den Dorpel MA, Van de Ven PJ, et al. Randomized, clinical trial comparison of trisodium citrate $30 \%$ and heparin as catheter-locking solution in hemodialysis patients. J Am Soc Nephrol. 2005;16:2769-77.

15. Solomon LR, Cheesbrough JS, Ebah L, et al. A randomized doubleblind controlled trial of taurolidine-citrate catheter locks for the prevention of bacteremia in patients treated with hemodialysis. Am J Kidney Dis. 2010;55:1060-8.

16. Sankey SS, Weissfeld LA, Fine MJ, et al. An assessment of the use of the continuity correction for sparse data in meta-analysis. Commun Stat Simul Comput. 1996;25:1031-56.

17. Kirkwood B. Essentials of medical statistics. 2nd ed. Blackwell Scientific Publishers Ltd, 9600 Garsington Road, Oxford, UK; 1998.

18. Altman DG, Bland MJ. Interaction revisited: the difference between two estimates. BMJ. 2003;326:219.

19. Begg CB, Mazumdar M. Operating characteristics of a rank correlation test for publication bias. Biometrics. 1994;50(4):1088-101. 
20. Egger M, Davey Smith G, Schneider M, et al. Bias in meta-analysis detected by a simple, graphical test. BMJ. 1997;315(7109):629-34.

21. Higgins JP, Thompson SG, Deeks JJ, et al. Measuring inconsistency in meta-analyses. BMJ. 2003;327:557-60.

22. Lau J, loannidis JP, Terrin N, et al. The case of the misleading funnel plot. BMJ. 2006;333:597-600

23. Tobias A. Assessing the influence of single study in the meta-analysis estimate. Stata Technical Bulletin. 1999;8(47):15-7.

24. Guyatt $G H$, Oxman AD, Schünemann HJ, et al. GRADE guidelines: a new series of articles in the Journal of Clinical Epidemiology. J Clin Epidemiol. 2011;64:380-2.

25. Huguet A, Hayden JA, Stinson J, et al. Judging the quality of evidence in reviews of prognostic factor research: adapting the GRADE framework. Syst Rev. 2013;2:71. doi: 10.1186/2046-4053-2-71

26. Center for reviews and dissemination: systematic review of clinical tests. In systematic reviews. CRD'S guidance for undertaking reviews in health care. York: CRD, Center for Reviews and Dissemination; 2008. p. 109-56.

27. Cohen J. Statistical power analysis for the behavioral sciences. 2nd ed. New York, NY: Academic Press; 1988.

28. Pervez A, Ahmed M, Ram S, et al. Antibiotic lock technique for prevention of cuffed tunnel catheter associated bacteremia. J Vasc Access. 2002;3:108-13.

29. MacRae JM, Dojcinovic I, Djurdjev O, et al. Citrate $4 \%$ versus Heparin and the reduction of thrombosis study (CHARTS). Clin J Am Soc Nephrol. 2008 Mar;3(2):369-74.

30. Al-Hwiesh AK, Abdul-Rahman ISA. Successful prevention of tunneled, central catheter infection by antibiotic lock therapy using vancomycin and gentamicin. Saudi J Kidney Dis Transplant. 2007;18:239-47.

31. Campos RP, do Nascimento M, Chula DC, et al. Minocycline-EDTA lock solution prevents catheter-related bacteremia in hemodialysis. J Am Soc Nephrol. 2011 October;22(10):1939-45.

32. Davanipur M, Pakfetrat M, Roozbeh J. Cloxacillin as an antibiotic lock solution for prevention of catheter-associated infection. IJKD. 2011;5:328-31.

33. Maki DG, Ash SR, Winger RK, et al. AZEPTIC Trial Investigators. A novel antimicrobial and antithrombotic lock solution for hemodialysis catheters: a multi-center, controlled, randomized trial. Crit Care Med. 2011 April;39(4):613-20.

34. Moran J, Sun S, Khababa I, et al. A randomized trial comparing gentamicin/citrate and heparin locks for central venous catheters in maintenance haemodialysis patients. Am J Kidney Dis. 2011;59(1):102-07.

35. Mortazavi M, Alsaeidi S, Sobhani R, et al. Successful prevention of tunneled, central catheter infection by antibiotic lock therapy using cefotaxime. J Res Med Sci. 2011 March;16(3):303-309.

36. Saxena AK, Al-hafiz A, Abu-Oyun B, et al. Cefotaxime-heparin lock prophylaxis against hemodialysis catheter-related sepsis among Staphylococcus aureus nasal carriers. Saudi J Kidney Dis Transpl. 2012;23(4):743-54.

37. Droste JC, Jeraj HA, MacDonald A, et al. Stability and in vitro efficacy of antibiotic-heparin lock solutions potentially useful for treatment of central venous catheter-related sepsis. J Antimicrob Chemother. 2003:51:849-55.

38. Fernandez-Gallego J, Martin M, Gutierrez E, et al. Prophylaxis of gentamicin locking of chronic tunneled central venous catheters does not cause bacterial resistance. Nefrologia. 2011;31(3):308-12.

39. Landry DL, Braden GL, Gobeille SL, et al. Emergence of gentamicinresistant bacteremia in hemodialysis patients receiving gentamicin lock catheter prophylaxis. Clin J Am Soc Nephrol. 2010;5(10):1799804
40. Centers for Disease Control and Prevention. Staphylococcus aureus resistant to vancomycin-United States, 2002. MMWR Morb Mortal Wkly Rep. 2002;51:565-7.

41. Raad I, Chatzinikolaou I, Chaiban G, et al. In vitro and ex vivo activities of minocycline and EDTA against microorganisms embedded in biofilm on catheter surfaces. Antimicrob Agents Chemother. 2003;47:3580-5.

42. Saxena AK, Panhotra BR. Locking hemodialysis catheters with cefotaxime instead of gentamicin to avoid potential ototoxicity. Kidney Int. 2005;67:2505-6.

43. Francisco IL, Mercedes P, Pedro O, et al. Cefotaxime twenty years later observational study in critically ill patients. Enferm Infecc Microbio Clin. 2001;19:211-8.

44. Polaschegg HD, Sodemann K. Safety of concentrated trisodium citrate catheter locks. Nephrol Dial Transplant. 2008;23:4075-4075.

45. Grudzinski L, Quinan P, Kwok S, et al. Sodium citrate 4\% locking solution for central venous dialysis catheters: An effective, more cost-efficient alternative to heparin. Nephrol Dial Transplant. 2007;22:471-6.

46. Safdar N, Maki DG. Inflammation at the insertion site is not predictive of catheter-related bloodstream infection with short-term, noncuffed central venous catheters. Crit Care Med. 2002;30(12):2632-5.

47. Abad CL, Safdar N. Catheter-related blood stream infections. Infectious diseases. Special ed. McMahon Publishing, New York, United States; 2011.

48. Sexton DJ. Vascular access infection in patients undergoing dialysis with special emphasis on the role and treatment of Staphylococcus aureus. Infec Dis Clin North Am. 2002;15:731-42.

49. Maar KA. Staphylococcus aureus bacteremia in patients undergoing hemodialysis. Semin Dial. 2000;13:23-9.

50. Li Y, Friedman JY, O'Neal BF, et al. Outcomes of Staphylococcus aureus infection in hemodialysis-dependent patients. Clin J Am Soc Nephrol. 2009:4:428-34.

51. Fowler Jr VG, Miro JM, Hoen B, et al. Staphylococcus aureus endocarditis. JAMA. 2005;293:3012-21.

52. Gonzalez C, Rubio M, Romero-Vivas J, et al. Bacteremic pneumonia due to Staphylococcus aureus: a comparison of disease caused by methicillin-resistant and methicillin-susceptible organisms. Clin Infec Dis. 1999;29: 1171-7.

53. Costerton JW, Stewart PS, Greenberg EP. Bacterial biofilms: a common cause of persistent infections. Science. 1999;284:1318-22.

54. O'Grady NP, Alexander M, Dellinger EP, et al. Guidelines for the prevention of intravascular catheter-related infections. MMWR Recomm Rep. 2002 Aug 9;51(RR-10):1-29.

55. Blot SI, Depuydt P, Annemans L, et al. Clinical and economic outcomes in critically ill patients with nosocomial catheter-related bloodstream infections. Clin Infec Dis. 2005 December;41(11):1591-8.

56. Allon M. Prophylaxis against dialysis catheter-related bacteremia: a glimmer of hope. Am J Kidney Dis. 2008 February;51(2):165-8.

57. Snaterse M, Rüger W, Scholte op Reimer WJM, et al. Antibioticbased catheter lock solutions for prevention of catheter-related bloodstream infection: a systematic review of randomised controlled trials. J Hosp Infect. 2010;75:1-11.

58. Yahav D, Rozen-Zvi B, Gafter-Gvili A, et al. Antimicrobial lock solutions for the prevention of infections associated with intravascular catheters in patients undergoing hemodialysis: systematic review and meta-analysis of randomized, controlled trials. Clin Infec Dis 2008;47:83-93. 